\title{
La figura del demonio y su función dramática en los autos sacramen- tales de Calderón ${ }^{\top}$
}

\section{The Devil and his Dramatic Function in Calderon's Autos Sacramentales}

\author{
Luis Iglesias Feijoo / Isabel Hernando Morata \\ Universidad de Santiago de Compostela \\ ESPAÑA \\ luis.iglesias.feijoo@usc.es / isabel_hernando86@hotmail.com \\ [Hipogrifo, (issn: 2328-1308), 2.1, 2014, pp. 7-22] \\ Recibido: 20-12-2013 / Aceptado: 14-02-2014 \\ DOI: http://dx.doi.org/10.13035/H.2014.02.01.02
}

Resumen. En algunos autos sacramentales de Calderón el personaje del Demonio idea la trama y plantea la acción dramática, actuando como un demiurgo. Traza planes y estratagemas para confundir al Hombre, pero fracasará siempre. Esta función acerca las obras al campo del metateatro. Se sugieren al final ciertos paralelos con Shakespeare.

Palabras clave. Calderón, Autos sacramentales, Demonio, Metateatro, Shakespeare.

Abstract. In some Calderón's autos sacramentales the character of the Devil draws the plot and establishes the dramatic action as a demiurge. He elaborates plans and strategies to confuse the Man, but he always fails. This function approaches the autos to the metatheater. Finally certain parallels with Shakespeare are suggested.

Keywords. Calderón, Autos sacramentales, Devil, Metatheatre, Shakespeare.

1. El presente trabajo se enmarca en el Proyecto de Investigación de la DGICYT dirigido por Luis Iglesias Feijoo FFI2012-38956, y en el Proyecto Consolider-Ingenio CSD2009-00033 sobre «Patrimonio teatral clásico español» TECE-TEl, conocido como TC/12, cuyo coordinador general es Joan Oleza, de la Universitat de València, que reciben fondos FEDER. Isabel Hernando Morata es beneficiaria de una Beca FPU del Ministerio de Educación. Una primera versión fue presentada en junio de 2012 en el Congreso Internacional «Teatro y fiesta popular y religiosa», celebrado en Cusco, Perú. Con posterioridad se ha publicado Moncunill, 2013, que en realidad reitera lo ya dicho en Moncunill, 2011; véanse las pp. 19-22, 234-239, 285-286 y 304-305. Se centra en los aspectos temáticos y antropológicos, por lo que no coincide con lo que aquí se presenta. 
El demonio carece de aliento trágico en el teatro de Calderón de la Barca². Su papel está definido antes de comenzar la acción y no se verá alterado por ninguna circunstancia. Él ha de preparar asechanzas contra los personajes, sean alegóricos o no, proponerles trampas, sugerirles engaños. Sin embargo, su fracaso está predeterminado y siempre acabará vencido. La razón es meridiana: desde su osada rebelión contra Dios, no puede hacer otra cosa que reiterar su incesante propósito, para ver cómo de manera inexorable este se derrumba con estrépito ante el triunfo de sus presuntas víctimas.

Dado este planteamiento, cabría rastrear las razones por las que un dramaturgo tan hábil como nuestro don Pedro vuelve una vez y otra a convocarlo a escena, con grave riesgo de incurrir en repeticiones o de provocar hastío en el auditorio. Ello es especialmente notable en el género de los autos sacramentales, pues de la comedia no nos vamos a ocupar aquí. Pero la respuesta es automática: siendo los autos un continuado y exhaustivo panorama del enfrentamiento del bien con el mal bajo los conceptos de la teología católica, la encarnación prototípica de ese mal debía ser presentada de forma ineludible.

Ahora bien, ese peligro de la reiteración era grande y sin duda el dramaturgo lo sabía muy bien. Quizá por ello planteó maneras diferentes de abordar su figura, que los estudiosos han puesto ya de relieve. Las variaciones en el plano conceptual eran escasas, pues los matices dogmáticos que la figura del demonio puede originar no son infinitos. Como nuestra especialidad no se centra en el campo de la religión, aquí los dejaremos completamente de lado, para centrarnos en aspectos sobre los que acaso podamos aportar alguna sugerencia de provecho. Nuestro enfoque reconoce y tiene en cuenta los fundamentos doctrinales y teológicos de los autos, pero se ubicará en el territorio literario y, más específicamente, en el teatral. Pues, si los autos formaron parte de la liturgia católica y no pueden entenderse sin conocerla, eran sin duda obras teatrales, destinadas a ser representadas ante un público variopinto al que había que atraer con las peripecias de la acción, lo sorprendente de la maquinaria escénica, el atractivo de música y canto y, desde luego, con el arte de actores y actrices.

Fue Alexander Parker quien primero señaló en su estudio fundamental sobre los autos de 1943 que la por él denominada teoría dramática de Calderón alcanza un grado especial de perfección en ciertas piezas de madurez. La imaginación creadora del autor idea un tema, que se encarna por medio de la alegoría en una obra concreta ( $Y$ Y pues ya la fantasía / ha entablado el argumento, / entable la realidad / la metáfora», según la cita de Las órdenes militares que utiliza para el caso3). Pres-

2. En el siglo XIX Patricio de la Escosura, 1875, p. 342, lo definía, en cambio, como «persona dramática eminentemente trágica». No parece querer decir sino que el enfoque que le da Calderón es serio, no cómico; no erraba Parker, 1959, p. 10, al calificar ese añejo trabajo como «estudio inadecuado: ejemplifica un acercamiento a Calderón completamente pasado de moda». Sin embargo, el propio Parker (1943, p. 94) había señalado que en algún auto el Demonio era una figura «más impresionante y trágica» (Parker, 1983, p. 84), pero con ello solo quería resaltar que nunca puede triunfar, aunque nunca pueda dejar de querer intentarlo. No hay el mínimo indicio de tragedia existencialista al modo de Sísifo.

3. Parker, 1983, p. 62. 
cindamos del hecho de que ese recurso no tiene tanto que ver con la teoría como con la práctica y pasemos también por alto que no es seguro que se trate de un rasgo de madurez, salvo si asumimos que en Calderón esta llegó muy pronto tanto en las comedias como en las obras sacramentales.

Lo que más importa es la aguda observación de que el proceso desplegado en los autos no solo es del todo inverosímil y antirrealista, cuestión que no suponía grave problema en tiempos de Calderón ni tiene por qué suponerlo hoy, sino que se hacía de transmisión complicada por su carácter exclusivamente conceptual, intelectual, y por ello de difícil concreción en una intriga dramática. Pero esa dificultad quedaba superada si se acudía a un recurso compositivo muy sagaz: como la acción desarrollada era el producto de una inteligencia discursiva (la de Calderón), «si la persona cuya mente la concibe aparece en escena, y si el proceso de su pensamiento y su proyección dramática se hacen así simultáneos, se dota a la acción» de mucha mayor entidad y capacidad de ser comprendida, pues ese personaje, si lo considera oportuno, está en disposición de comentar los puntos que desee de aquello que esta ideando ${ }^{4}$.

Al hilo de su análisis, Parker apuntó que ese personaje que planea la acción es a menudo el Demonio, que inventa estratagemas para confundir y pervertir al hombre. Aporta un par de ejemplos y pasa luego a examinar otros aspectos ${ }^{5}$. Estudiosos posteriores no han dejado de seguir sus pasos, y así profundizaron en su planteamiento Cilveti, Kurtz, Díaz Balsera o Martin ${ }^{6}$. Y, con todo, parece que no se han agotado las consecuencias que cabe extraer de las observaciones ya apuntadas. Nuestro intento es por ello incidir en este recurso que se utiliza para configurar la totalidad de la trama de algunos de los autos y que, en última instancia, remite al despliegue de una de las posibilidades de lo que en términos críticos modernos se ha denominado el metateatro. A tal fin, trataremos solo unos pocos ejemplos, pues la amplitud de este procedimiento constructivo en Calderón merecería una completa monografía.

El concepto de metateatro fue acuñado en 1963 por Lionel Abel. Se ha destacado que su propuesta no era ni muy sistemática, ni muy rigurosa, ni muy exhaustiva. Ello es cierto, pero no lo es menos que supuso un punto de inflexión para revelar la existencia de todo un sector de la creación dramática que hasta entonces no había merecido un enfoque preciso. Aparte de la insistencia en enfrentar metateatro con tragedia, lo que dista de estar justificado, Abel resalta lo propio de cierto tipo de obras: «Only certain plays tell us at once that the happenings and characters in them are of the playwright's invention». Su carácter de ficciones diseñadas por un

4. Parker, 1983, p. 72

5. Parker, 1983, pp. 81-84. Antes de Parker solo había algunas alusiones de pasada, como McGarry, 1937, p. 39, o Weir, 1940, p. 15

6. Cilveti, 1977; Cilveti, 1981; Kurtz, 1991, pp. 177-183 (se centra en autos diferentes a los que aquí nos ocupan); Díaz Balsera, 1997, especialmente el capítulo 4, pp. 81-97, sobre El jardín de Falerina; Martin, 2002. En el estudio preliminar al volumen que inicia le serie de ediciones críticas de los autos, señalan Arellano y Cilveti: «En la mayoría de los autos calderonianos es el demonio el que inventa y aplica la alegoría ordenando el material del argumento» (en El divino Jasón, 1992, p. 64). 
escritor las presenta como el producto de alguien que las imagina; muestran «the reality of the dramatic imagination» ${ }^{7}$.

Entre los ejemplos que discute figuran Shakespeare y Calderón como prototipos. Pero del dramaturgo español se centra en La vida es sueño y no hay una sola palabra sobre los autos, con los que probablemente Abel no tenía familiaridad alguna. En la amplia bibliografía que el metateatro ha originado hasta hoy, pocos son los estudios que hacen ahora al caso. Las monografías de carácter general prestan escasísima atención a la dramaturgia española ${ }^{8}$. Dentro de la tipología propuesta por Hornby, una de los más sugestivas, la que más interesa es la quinta especie, «Self-Reference», pero sin adecuarse del todo a nuestro intento ${ }^{9}$. Por su parte, las aportaciones realizadas desde el hispanismo han sido a menudo agudas y oportunas, pero se han centrado de forma casi exclusiva en la comedia y, si se acercan al auto sacramental, parecen agotarse en el tratamiento de El gran teatro del mundo ${ }^{10}$.

Sin embargo, los aspectos más fecundos del concepto de metateatro no residen principalmente en la fórmula más evidente que puede adquirir en escena, la de la obra dentro de la obra, «play-within-a-play», sea en sentido literal o figurado, es decir, en el recurso de incluir la representación de una obra teatral dentro de la obra teatral, como en Hamlet, o por el que supone fingir una realidad fabricada como si fuera de verdad, como se hace con Segismundo o como la desarrollaría Evreinov en el siglo XX.

Para dejarlo claro desde ahora, la modalidad más sorprendente es la de presentar una obra que revela y subraya su propia teatralidad, es decir, que expone su técnica y funcionamiento ante el espectador al consistir en el desarrollo de una intriga, acción o trama -como queramos llamarla- que es ideada por un personaje. De esta manera, se evita cualquier confusión con la realidad, algo por otra parte común al teatro europeo de la época, del todo ajeno a cualquier noción de 'realismo'. El espectador tiene ante sí una obra que expone con contundencia que es el designio de alguien, un personaje que la propone y que, por supuesto, asume la función vicaria del propio autor. Lo que se ve y oye es una construcción, algo fingido por alguien que lo planea y a cuyo despliegue asistimos hasta el desenlace. No se elimina la ficción, se la potencia al resaltar que lo es.

Nunca resulta este planteamiento más oportuno que en el caso de los autos, que por definición ya son inverosímiles y antirrealistas. Como antes se apuntó,

7. Abel, 1963, p. 59.

8. Algunos, porque trabajan un campo diferente, como la escena francesa en Forestier, 1996. Otros, porque sencillamente la despachan con una mención de pasada, como Schmeling, 1982, o Kowzan, 2006. 9. Hornby, 1986.

10. Como no es del caso dar ahora una cumplida referencia de la bibliografía existente, puede consultarse la que se menciona en el reciente número de la revista electrónica Teatro de palabras, núm. 5, y en concreto la presentación que llevan a cabo Hermenegildo, Rubiera y Serrano, «Más allá de la ficción teatral: el metateatro». Son sumamente interesantes los planteamientos de Suárez, 2002, y Thacker, 2002, el primero por el tratamiento de la imaginación y el segundo por su desarrollo del concepto del metateatro, pero ambos se ciñen al mundo de la comedia sin extenderse al auto. Sobre El gran teatro, Reyes Anzaldo, 2011. Para la bibliografía de los autos en general, Cilveti y Arellano, 1994. 
el trabajo con alegorías no produce equívocos. Por tanto, si como espectadores se nos ofrece una obra cuya acción consiste en ejecutar lo que la mente de un personaje-demiurgo ha planificado, pasamos al campo del metateatro y estamos dispuestos a entender el despliegue de acciones y parlamentos como el resultado de un plan concebido por alguien. En cierto modo, presenciamos el propio pensamiento, el contenido de la mente, un tanto a la manera que desarrollaría mucho tiempo después Arthur Miller en Death of a Salesman, cuyo primer título iba a ser The Inside of His Head ${ }^{11}$.

Este procedimiento se encuentra ya en un auto bastante temprano, El gran teatro del mundo. Pero, por lo dicho antes, no se trata de que en él se emplee la vieja imagen del mundo como teatro, que también lo introduce en el territorio del metateatro, por supuesto. Lo que más importa es observar de qué forma la intriga es el resultado de lo que el personaje del Autor ha imaginado: «hoy, de un concepto mío / la ejecución a tus aplausos fío. / Una fiesta hacer quiero» (VP, pp. 203-204) ${ }^{12}$. Como siempre es muy atractivo representar obras teatrales, «una comedia sea / la que hoy el cielo en tu teatro vea» (p. 204). Y, además del cielo, verán la comedia de la vida los espectadores, ante los que representarán esos hombres que son los actores de la compañía en un doble sentido, porque lo son literalmente y porque lo son alegóricamente, en esa compañía cuyo Autor, es decir, empresario, repartirá con cuidado los papeles.

Son múltiples las consecuencias que extrae Calderón de este planteamiento que aquí no vamos a considerar, para ceñirnos a ciertos autos en los que quien planea la acción es el personaje del Demonio, sea con este nombre o con algún otro similar: Luzbel, Lucero... No se olvide que este último término viene del latín lucifer. Ya quedó dicho que Parker destacó el papel que asume de creador de la intriga y Cilveti desarrolló bastante más el análisis del recurso, aunque acaso más preocupado por las resonancias teológicas que por las teatrales. Como los autos implicados son demasiados, conviene reducir a seis el examen de aquellos en los que el Demonio traza un engaño para que el Hombre se condene, plan cuya elaboración, desarrollo y fracaso constituye la estructura: No hay más Fortuna que Dios, El valle de la Zarzuela, El diablo mudo, El Pastor Fido, Andrómeda y Perseo y La divina Filotea ${ }^{13}$.

11. Véanse las palabras del autor en Miller, 1967, p. 154.

12. Se citan siempre los autos por la edición crítica de cada uno de ellos en la serie dirigida por Ignacio Arellano desde Pamplona, recogidos en la bibliografía final, con indicación en el texto de las páginas oportunas. Para mayor comodidad, también se incluye luego, precedida de la sigla VP, la página respectiva en la edición de los autos de Ángel Valbuena Prat, Calderón, Autos sacramentales, que difiere muy poco en los textos que se citan; la $2^{\mathrm{a}}$ ed. de Valbuena, 1967, hecha a plana y renglón, introduce erratas. 13. Cilveti, 1977, p. 21, afirma que el Demonio aparece en sesenta y un autos calderonianos; actúa solo en tres, en treinta y uno está personificado en el Pecado, la Culpa u otro personaje y en veintisiete figura acompañado de Malicia, Culpa u otro ser (pp. 41-42). El mismo autor ofrece una lista de obras en las que el Demonio elabora la alegoría principal (p. 111), lista incompleta, pues no incluye algunos de los autos tratados en el presente trabajo. 
El mecanismo consiste en que casi siempre al iniciarse el auto ${ }^{14}$, el Demonio dialoga con otros personajes: con la Malicia en No hay más Fortuna que Dios (pp. 125-133; VP, pp. 615-617); con la Culpa en El valle de la Zarzuela (pp. 75-101; VP, 700-703) y en El Pastor Fido (pp. 89-113; VP, pp. 1585-1590); con el Mundo y la Lascivia en La divina Filotea (pp. 75-89; VP, pp. 1774-1777); con el Hombre en El diablo mudo (pp. 107-113; VP, pp. 942-943); y con Medusa en Andrómeda y Perseo (pp. 179-198; VP, pp. 1699-1702). Casi todos son aliados suyos, pues ante ellos expone «cautelosas industrias», como él mismo las denomina ${ }^{15}$, y les pide su colaboración ${ }^{16}$. Algo extraño ocurre en El diablo mudo (pp. 111-113; VP, pp. 942-943), en el que sin ningún secreto asegura al Hombre que impedirá la satisfacción de su culpa.

Después de comunicar los motivos por los que actúa -el mejor ejemplo es acaso la narración de «aquella primera lid» en El valle (p. 77; VP, p. 701)-, el Demonio expresa su ansia por vengarse de Dios; como ha notado Cilveti ${ }^{17}$, en su discurso abunda el léxico propio del código del honor: «en venganza de este oprobio», en Andrómeda y Perseo (p. 202; VP, 1702); «vengue mis ruinas yo», en La divina Filotea (p. 81; VP, p. 1776). Su estratagema está encaminada a frustrar los planes divinos: intenta hacer creer al Hombre que la responsable del reparto de estados y bienes no es la Justicia Distributiva, sino la Fortuna en No hay más Fortuna que Dios; en El valle de la Zarzuela, su propósito es impedir el triunfo de la segunda venida de Cristo; en El diablo mudo, evitar que la Humanidad sea perdonada; en Andrómeda y Perseo, enamorar a Andrómeda (la Naturaleza Humana) o evitar que ame a ningún otro; en La divina Filotea, por último, apoderarse de Filotea, alegoría del Alma, que espera en un castillo al Príncipe de la Luz.

Para salirse con la suya, el Demonio recurre a la magia: «componme un hechizo», le pide a Medusa en Andrómeda (p. 186; VP, p. 1700), y en El diablo mudo (pp. 132-136; VP, pp. 945-946) priva de los sentidos al Hombre para que ni vea la imagen de su muerte en un espejo, ni pueda confesarse ante la Penitencia, ni escuche a la Fe. También utiliza el engaño y la tentación: él mismo se refiere a «una mentira» en No hay más Fortuna (p. 127; VP, p. 616) y al «simulado doblez», en La divina Filotea (p. 88; VP, p. 1777), y el Albedrío se deja llevar por el «apetecido antojo / de las manzanas de un árbol» en Andrómeda y Perseo (p. 198; VP, p. 1702) ${ }^{18}$.

Lo más interesante de este planteamiento es que la cautela ideada por el Demonio es al tiempo la alegoría que se desarrolla a lo largo del auto; por ello este per-

\footnotetext{
14. No siempre: en Andrómeda y Perseo, Andrómeda habla con el Albedrío, la Gracia, la Inocencia, la Voluntad y la Ciencia antes de la irrupción del Demonio; Ruano de la Haza, en Calderón, Andrómeda y Perseo, p. 31, observa que Andrómeda se encuentra en este momento «en su estado edénico». 15. No hay más Fortuna, p. 130; VP, p. 616. También en El valle, pp. 81 y 82; VP, p. 701, emplea los términos «industria» y «cautela».

16. En El diablo mudo, p. 124; VP, p. 944, requerirá la ayuda de El Apetito.

17. Cilveti, 1977, p. 212

18. Cilveti, 1977, p. 215, por su parte, observa que los medios empleados por el Demonio «se reducen a la tentación, la obsesión y la magia».
} 
sonaje ha sido bautizado como «director escénico»19. El vínculo entre la invención de la trama y su montaje lo advierte Parker para No hay más Fortuna que Dios ${ }^{20}$ : la acción es un «práctico concepto» que encierra un «concepto imaginado»; el pensador del concepto sobre el escenario es el Demonio. Varios críticos han reparado ya en unos versos de este auto (p. 130; VP, p. 616):

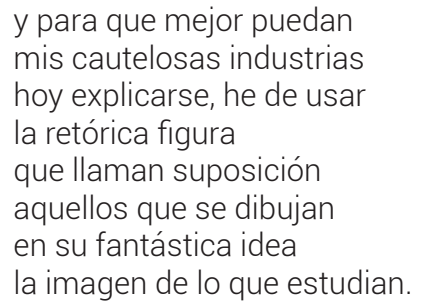

Nos hallamos en la médula del metateatro: el Demonio confiesa que va a usar la figura llamada «suposición», definida por él mismo como una imagen dibujada en su mente (la «fantástica idea»), esto es, el argumento del auto ${ }^{21}$. Después expone la relación entre los elementos del escenario y su significado en la representación (pp. 130-131; VP, pp. 616-617) ${ }^{22}$ :

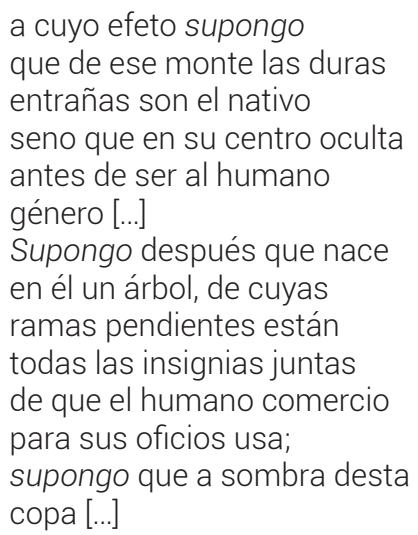

19. García Valdés, en Calderón, El diablo mudo, p. 26. También Martin, 2002, p. 220, lo llama «director de escena».

20. Parker, 1949, pp. XXVI-XXVII.

21. Arellano, 1995, pp. 693-694, explica el sentido de estos términos: «la alegoría viene a ser el método de invención y producción del auto sacramental [...] Las 'suposiciones' son las hipótesis parciales de la alegoría, que es la hipótesis total del auto. En efecto, la alegoría funciona en el auto en calidad de hipótesis de trabajo encaminada a verificar el proyecto expresado por uno o más personajes por medio de hipótesis parciales, cada una de las cuales contribuye a la obtención de la 'fantástica idea' o argumento del auto de que se sirve la alegoría». En p. 694 alude a los versos reproducidos de No hay más Fortuna de Dios, que también comenta Cilveti, 1977, p. 99. También Calderón, El Año Santo de Roma, pp. 28-31. Para una sutil reflexión sobre la suppositio en este auto, Woodward, 1985.

22. Las cursivas son siempre añadidas. En Psiquis y Cupido para Madrid (p. 369) aparece El Odio ideando la trama, dice tres veces «supongo» y añade: «quiero, para que mejor / se entienda el concepto mío, / que una representación / me lo explique». 


\author{
supongo \\ que la Justicia sacuda \\ con su vara aquellas hojas..
}

La alegoría de La divina Filotea (p. 82; VP, p. 1776) es construida por el Demonio con esta misma técnica23.

\author{
Suponed, pues, que el humano \\ cuerpo es un castillo en quien \\ por resguardarla de mí \\ quiere el esposo que esté \\ como en depósito el alma.
}

Las expresiones que manifiestan la creación de la alegoría por parte del Demonio y su concreción escénica pueden variar. Este, como un verdadero autor de comedias - 0 , valga la redundancia, autor de autos- señala en No hay más Fortuna que Dios: «Y porque no solo en sombras / imaginadas discurras, / [...] / vuelve al peñasco los ojos: / verás que en vagas figuras / te represento en su escena / un árbol» (p. 132; VP, p. 617), y en El valle de la Zarzuela: «hoy ha de ser de mi idea / una representación / de caza» (pp. 92-93; VP, p. 702). En esta misma obra define también su plan: «inventando hoy una nueva / parábola», y descubre luego el valor simbólico del objeto que lleva la Culpa: «esa dorada copa / de sangre de áspides llena / es un emblema que dice / lisonja a un tiempo y ofensa» (p. 95; VP, pp. 702-703). Nada más coherente que, cuando sus planes se tuercen, exclame: «iOh!, nunca hubiera / desta alegórica caza / inventado mi cautela / la metáfora» (pp. 153-154; VP, p. 714). En La divina Filotea (p. 85; VP, p. 1776) aludirá por su parte a que «más / importa acudir a él [su intento] / que a la metáfora, el día / que ya asentada una vez / notoria queda»; y en Andrómeda y Perseo (p. 186; VP, p. 1700): «si como a culpa te invoco [...] / y si en retóricos tropos / de alegórico concepto, / como a Medusa te nombro...» ${ }^{24}$.

23. Martin, 2002, pp. 133-146, observa la enunciación de suposiciones también en tres autos de fecha próxima: El maestrazgo del Toisón, en el que el papel activo lo encarna la Malicia, que viste «de galán, con alguna alusión de demonio en el manto o vestido» (VP, p. 894), Las espigas de Ruth, en el que habla la Discordia, que sigue siempre a El Lucero, esto es, al demonio, y Las órdenes militares, donde es la Culpa quien habla. En los tres autos se pronuncia tres veces en cada uno: «Supongamos...» (El maestrazgo, VP, pp. 896; Las espigas, p. 103; VP, p.1093; y Las Órdenes, pp. 80-81; VP, p. 1019). Sobre el tercero de estos autos, también Kurtz, 1991, pp. 143-144.

24. También otros personajes aluden a alegorías y metáforas: «Júpiter, dios de los dioses, / si a la metáfora torno / - pues ya de otros empezada / fuerza es seguirla nosotros-», dice Medusa en Andrómeda y Perseo, pp. 187-188; VP, p. 1700; y el Judaísmo en La divina Filotea, p. 109; VP, p. 1781: «al Príncipe de la Luz / -si a la metáfora vuelvo-». Kurtz, 1991, pp. 177-180, analiza el empleo de estos términos o similares en otros autos: «industria», «representable idea», «retóricos tropos», «alegoría», «parábolas», «metáfora», «concepto», «imaginada scena» en La redención de cautivos, pp. 64-66 y 72; VP, pp. 1323 y 1325; «fantásticas ideas», «industria», «idea», «fábula», «fingida / o representable scena» en El jardín de Falerina, pp. 78 y 85-86; VP, pp. 1507 y 1509; «alegoría / de poética ficción» en Psiquis y Cupido para Madrid, VP, p. 369, o «representable objeto / de metafórico asunto» en Las órdenes militares, p. 80; VP, p. 1019. 
Otras expresiones metateatrales evidencian que el Demonio dirige el avance del auto; al Hombre le dice: «atiende cómo empieza desde aquí / la representación» (El diablo mudo, p. 112; VP, 942), y más adelante (p. 124; VP, p. 944): «pasando la escena / va de historia a alegoría»; y en La divina Filotea: «que quizá lo que ahora idea / será realidad después» (p. 82; VP, p. 1776). Se trata, por tanto, de que el personaje tiene un proyecto, que en El Pastor Fido designa como «mi principal intento» (p. 104; VP, p. 1587; «nuestro intento» se dice en La divina Filotea, p. 85; VP, p. 1776). Para llevarlo a cabo, «discurramos con qué astucias, / con qué insidias, con qué medios» (El Pastor, pp. 104-105; VP, p. 1587) se puede realizar. En diálogo con la Culpa, se encuentra uno: «Pues en un concepto estamos, / sepamos si en un concepto, / visto a dos luces, habrá / o verdad o fingimiento», y la Culpa lo concreta: «A mí un medio / de fingimiento y verdad, / en metáfora compuesto, / se me ofrece» (p. 109; VP, p. 1589 $)^{25}$. Y se explica claramente el proceso que no ya Culpa y Demonio, sino el mismo don Pedro Calderón ha llevado a cabo (p. 110; VP, p. 1589):

\author{
Si para especulación \\ de los más altos misterios \\ se han de valer los humanos \\ de parábolas o ejemplos, \\ que a su modo los explican, \\ si los que los oigan, ciegos \\ de la luz de fee al oírlos, \\ han (o bárbaros o necios) \\ de viciarlos, sus verdades \\ en fábulas convirtiendo, \\ usemos nosotros hoy \\ de tal arte que sea a un tiempo \\ o parábola a su modo, \\ o fábula al modo nuestro.
}

La ejecución del plan suele comenzar bien para el Demonio, quien, en ocasiones escondido ${ }^{26}$, observa cómo los personajes que representan al Hombre caen en sus trampas y se alejan de Dios. Según afirma Parker para No hay más Fortuna: «The body of the auto shows, in terms of ordinary experience, that it is natural for men to behave foolishly $\rangle^{27}$ : uno de los engañados en este auto, el Poder, afirma (p. 145; VP, p. 620): «mi Fortuna, / a quien por dueño conozco», y Andrómeda acaba probando la fruta prohibida en la obra que protagoniza (p. 219; VP, p. 1705). Antes de sucumbir, el Hombre a veces duda; en El valle, afirma: «pues mortal / soy, la Gracia seguiré» (p. 121; VP, p. 708), y la Culpa le responde «Eso es serlo ahora, pudiendo

25. En Psiquis y Cupido para Madrid, VP, p. 369, se dice también: «quiero, para que mejor / se entienda el concepto mío, / que una representación / me lo explique». Rull, 2004, p. 196, destaca el carácter de «teatro en el teatro» de tal planteamiento.

26. Oculto entre unas peñas permanece con la Culpa en El valle de la Zarzuela, p. 140; VP, p. 711; también se esconde con Medusa en Andrómeda, p. 198; VP, p. 1702. El Demonio también se encubre con el disfraz (Cilveti, 1977, p. 216): aparece como un león en El valle, p. 69; VP, p.700; «a lo judío» en El diablo mudo, p. 199; VP, p. 957; y como monstruo marino en Andrómeda, p. 173; VP, p. 1698 27. Parker, en Calderón, 1949, p. XXIX. 
/ dejarlo para después.» Y cambia entonces de opinión: «También dices bien tú». $Y$ es que diversos «intermediarios» entre el Hijo de Dios y el Hombre avisan a este de los peligros de seguir al Demonio y sus cómplices: en No hay más Fortuna..., la Justicia intenta convencer a los engañados de que no deben seguir a la Fortuna (pp. 142-148; VP, pp. 619-621) y, para que huyan de la Culpa, la Gracia les grita a los continentes en El valle de la Zarzuela: «iEsperad, tened! / No sigáis de aquesa voz / los enamorados ecos» (p. 106; VP, p. 705). Otras veces quien advierte de la trampa tendida por el Demonio es el propio Cristo o una de sus figuras: Perseo le ruega a Andrómeda que no coma ningún fruto (pp. 209-210; VP, p. 1703); el Príncipe de la Luz anima a Filotea para que no deje de luchar contra quien asedia su castillo ( $L a$ divina Filotea, pp. 102-103; VP, p. 1780).

El Demonio monta en cólera cuando nota la reticencia del Hombre o tiene noticia de la llegada de un Salvador: en El diablo mudo (p. 208; VP, p. 959), acaba por golpear rabioso al Apetito; también siente miedo y desconcierto; «iOtra vez / y otras mil tu voz me pasma, / me atemoriza y asombra!», le dice al Príncipe en El valle (p. 166; VP, p. 716); en El Pastor Fido se pregunta: «¿Qué Pastor será aquel, jcielos!, / que al verle dudé y temí?», p. 127; VP, p. 1593); a Perseo inquiere: «¿Quién eres?» (Andrómeda, p. 253; VP, p. 1711), y en La divina Filotea (pp. 135 y 141; VP, pp. 1787 y 1789) consulta con el Mundo en dos ocasiones si sabe quién es el que ha llegado de los mares. Como subraya Cilveti: «La alusión al tormento (rencor, despecho...) diabólico es el supuesto constante y explícito»²8.

Si falla el plan inicial, sigue luchando por la caída del Hombre con otras tácticas: en No hay más Fortuna..., cuando el Bien se enfrenta al Mal, algo que no estaba previsto, la Malicia les cambia las capas para que sean confundidos (p. 155; VP, p. 622); tienta de tres maneras al Príncipe de El valle (pp. 164-166; VP, p. 716), con cuya aparición no contaba; en El diablo mudo amenaza: «revistiendo / en siete espíritus míos / [...] mi furor, he de volver / a la lid [...] / eligiendo al Judaísmo» (pp. 211-212; VP, p. 960). En El Pastor Fido explota también su ira: «Muera, que aunque mi dolor / no haya de morir con ella, / baste que muera la ira / de haber de vivir ajena; / y así, a complacer mi saña...» (p. 169; VP, p. 1603).

Pero el Mal siempre fracasa. Al final los engañados se desengañan y los hechizados se ven libres de su hechizo. Una de las representaciones más efectistas de este momento pertenece a No hay más Fortuna que Dios (pp. 187-190; VP, pp. 630-631), pues el Poder, la Milicia, el Pobre y la Labranza, que adoraban a la Fortuna, se dan cuenta de su extravío cuando la Hermosura se hunde en un escotillón, del cual sale después un Esqueleto. El Demonio, frustrado, no oculta su ira en plena exaltación de la Eucaristía. El auto concluye con cantos de alabanza y chirimías y él se queda, según sus propias palabras, «infeliz / para siempre» (p. 204; VP, pp. 634).

En suma, los planes del demonio no pueden sino conducir al fracaso. Como señalamos al principio, todo el público sabía cuál iba a ser el desenlace. El interés había que ubicarlo en otros recursos; Calderón hizo uso reiterado de uno de ellos, que consistía en resaltar el carácter intelectual de alegorías y metáforas, haciendo

28. Cilveti, 1977, p. 98. 
de la totalidad del auto el despliegue de un plan ideado por el personaje del Demonio; «el auto sería, pues, el desarrollo de esta fantasía del Demonio trasladado en figuras dramáticas que encarnan las suposiciones», en palabras muy recientes de Arellano, que destaca asimismo lo elaborado de su personaje: «este es un Demonio calderoniano y además de escolástico es sumamente conceptista; sus correspondencias y articulaciones poéticas son de extraordinario rigor ingenioso además de doctrinal» ${ }^{29}$. Se trataba, pues, de enfrentar al público con el desarrollo de una idea, es decir, de algo emanado de la mente, que se exponía en detalle para ser encarnado luego en la acción llevada a cabo por el conjunto de personajes. Todo procede del pensamiento, porque este es libre de imaginar lo que desee. Ya lo dice el mismo Calderón en No hay instante sin milagro (p. 123; VP, p. 1348):

\section{No lo dudes,}

que siendo el Pensamiento a quien acudes,

¿quién quita al Pensamiento

que finja fantasías en el viento?

No se evitaba así la inverosimilitud, se la potenciaba, según hemos dicho. No se quería esquivar que todo era ficción, imaginación, teatro. En efecto, el público va a presenciar una historia fingida por alguien, ideada por alguien. Se asiste a una obra teatral (un auto) que consiste en ser el plan de un demiurgo, que despliega su propia obra. Teatralidad de segundo grado, por lo tanto, que es así reclamada y proclamada. No hay equívocos, como no los hay en Shakespeare, cuando en The Life of King Henry $V$ hace decir al Coro que el espectador está en un teatro y que va a presenciar una obra:

O for a muse of fire, that would ascend

The brightest heaven of invention,

A kingdom for a stage

[¡Oh! ¡Quién tuviera una musa de fuego para escalar el cielo más resplandeciente de la invención! ¡Un reino por teatro!] $]^{30}$

Pero como no tiene a su disposición ese «kingdom», ha de conformarse con representar en «this cockpit» («Este circo de gallos»), «this wooden O» («esta O de madera»). Por tanto,

O pardon, since a crooked figure may

Attest in little place a million,

And let us, ciphers to this great account,

On your imaginary forces work.

Suppose within the girdle of these walls

Are now confined two mighty monarchies, 
[¡Oh!, perdón, ya que una reducida figura ha de representaros un millón en tan pequeño espacio, y permitidme que contemos como cifras de ese gran número las que forje la fuerza de vuestra imaginación. Suponed que dentro de este recinto de murallas están encerradas dos poderosas monarquías] ${ }^{31}$

Será necesario que el público supla «with your thoughts» (es decir, «con vuestros pensamientos»), las insuficiencias del espectáculo: «Think, when we talk of horses, that you see them» («Cuando os hablemos de caballos, pensad que los veis»). Y ello será factible, porque el espíritu camina rápido. Por eso, en el inicio del acto segundo, el Coro podrá encararse de nuevo con el público y subrayar con ironía que hay que cambiar de lugar,

\author{
...and the scene \\ Is now transported, gentles, to Southampton. \\ There is the playhouse now, there must you sit.
}

[Y la escena se ha transportado ahora, caballeros, a Southampton. Aquí está en estos momentos nuestro teatro y aquí es menester que os personéis] $]^{32}$

Pero ha de ser la intervención del Coro al comienzo del tercer acto la que interese más a nuestro propósito.

Thus with imagined wing our swift scene flies In motion of no less celerity

Than that of thought. Suppose that you have seen...

[He aquí cómo, sobre las alas de la imaginación, vuela rápida nuestra escena con una celeridad que no cede a la del pensamiento. Suponed...] $]^{33}$

Y prosiguen las apelaciones al espectador: «O, do but think [...] Work, work your thoughts, and therein see a siege [...] Suppose th'ambassador from the French comes back [...] Still be kind, / And eke out our performance with your mind» («iOh! Tratad de pensar [...] Haced trabajar, haced trabajar vuestros pensamientos y contemplad un sitio [...] Suponed que el embajador de los franceses ha llegado [...] Continuad siendo complaciente y suplid con el pensamiento las imperfecciones de nuestra representación» ${ }^{34}$ ). Al comenzar el acto $\vee$ vuelve el Coro a impulsar la mente del público: «So swift a pace hath thought that even now / You may imagine him upon Blackheath» («El pensamiento va con paso tan rápido, que, apenas dicho, podéis imaginarle en Blackheat») ${ }^{35}$. Por ello, la obra se despide con el 'Perdonad sus muchas faltas' al modo inglés, dirigiéndose, cómo no, a la mente de los espectado-

31. Shakespeare, King Henry V, pp. 120-121, y Shakespeare, Obras completas, p. 516.

32. Shakespeare, King Henry V, p. 155, y Shakespeare, Obras completas, p. 523.

33. Shakespeare, King Henry V, p. 198, y Shakespeare, Obras completas, p. 532.

34. Shakespeare, King Henry V, pp. 199-201, y Shakespeare, Obras completas, p. 532.

35. Shakespeare, King Henry V, p. 333, y Shakespeare, Obras completas, p. 561. 
res: «In your fair minds let this acceptance take» («que vuestra benévola opinión se digne aceptar el presente») $)^{36}$.

No hay gran trecho entre ese Coro que apela al espectador y lo lleva y lo trae y le indica dónde está y qué sucede en las elipsis y le incita a suponer, esto es, a imaginar hechos y circunstancias, y el personaje del Demonio que trama sus planes y lo obliga también a suponer las condiciones elementales para que el auto tenga lugar. En suma, dos grandes dramaturgos del XVII han coincidido en recursos bastante próximos para subrayar el carácter teatral del teatro, si queremos decirlo así. Todo es convención, todo puede ser presentado, la historia de unos reyes del pasado o la lucha y el enfrentamiento entre potencias anímicas o espirituales. Basta con que el espectador lo imagine, es suficiente que acepte la propuesta que el dramaturgo le presenta directamente, o a través de un personaje como el Demonio, que en los autos va a desplegar con reiterada insistencia sus asechanzas contra el género humano. Siguiendo sus planes seguimos la obra; observando su desarrollo asistimos a la encarnación de un objetivo que, no por acabar siempre en fracaso, puede poseer menos interés y despertar menos complacencia. A ello se dedicó Calderón al escribir buena parte de sus autos sacramentales.

\section{BIBLIOGRAFÍA}

Abel, Lionel, Metatheatre. A New View of Dramatic Form, New York, Hill and Wang, 1963.

Arellano, Ignacio, Historia del teatro español del siglo XVII, Madrid, Cátedra, 1995.

Calderón de la Barca, Pedro, No hay más Fortuna que Dios, ed. Alexander A. Parker, Manchester, Manchester University Press, 1949.

Calderón de la Barca, Pedro, Obras Completas. Tomo III. Autos sacramentales, ed. Ángel Valbuena Prat, Madrid, Aguilar, 1952.

Calderón de la Barca, Pedro, El divino Jasón, ed. Ignacio Arellano y Ángel L. Cilveti, Pamplona/Kassel, Universidad de Navarra/Reichenberger, 1992.

Calderón de la Barca, Pedro, El Año Santo de Roma, ed. Ignacio Arellano y Ángel L. Cilveti, Pamplona/Kassel, Universidad de Navarra/Reichenberger, 1995.

Calderón de la Barca, Pedro, Andrómeda y Perseo, ed. José María Ruano de la Haza, Pamplona/Kassel, Universidad de Navarra/Reichenberger, 1995.

Calderón de la Barca, Pedro, No hay instante sin milagro, ed. Ignacio Arellano, Ildefonso Adeva y Rafael Zafra, Pamplona, Universidad de Navarra/Kassel, Reichenberger, 1995.

Calderón de la Barca, Pedro, El diablo mudo, ed. Celsa Carmen García Valdés, Pamplona/Kassel, Universidad de Navarra/Reichenberger, 1999. 
Calderón de la Barca, Pedro, El pastor Fido, ed. Fernando Plata Parga, Pamplona/ Kassel, Universidad de Navarra/Reichenberger, 2003.

Calderón de la Barca, Pedro, Las Órdenes Militares, ed. José María Ruano de la Haza, Pamplona/Kassel, Universidad de Navarra/Reichenberger, 2005.

Calderón de la Barca, Pedro, La divina Filotea, ed. Luis Galván, Pamplona/Kassel, Universidad de Navarra/Reichenberger, 2006a.

Calderón de la Barca, Pedro, Las espigas de Ruth, ed. Catalina Buezo, Pamplona/ Kassel, Universidad de Navarra/Reichenberger, 2006b.

Calderón de la Barca, Pedro, El jardín de Falerina, ed. Luis Galván y Carlos Mata Induráin, Pamplona/Kassel, Universidad de Navarra/Reichenberger, 2007.

Calderón de la Barca, Pedro, No hay más Fortuna que Dios, ed. Ignacio Arellano, Pamplona/Kassel, Universidad de Navarra/Reichenberger, 2013.

Calderón de la Barca, Pedro, El valle de la Zarzuela, ed. Ignacio Arellano, Pamplona/ Kassel, Universidad de Navarra/Reichenberger, 2013.

Calderón de la Barca, Pedro, La redención de cautivos, ed. Marcela Trambaioli, Pamplona/Kassel, Universidad de Navarra/Reichenberger, 2013.

Cilveti, Ángel L., El demonio en el teatro de Calderón, Valencia, Albatros, 1977.

Cilveti, Ángel L., «Dramatización de la alegoría bíblica en Primero y Segundo Isaac de Calderón», en Critical perspectives on Calderón de la Barca, Frederick A. de Armas, David M. Gitlitz y José A. Madrigal, eds., Lincoln, Nebraska, Society of Spanish and Spanish-American Studies, 1981, pp. 39-52.

Cilveti, Ángel L. e Ignacio Arellano, Bibliografía crítica para el estudio del auto sacramental con especial atención a Calderón, Pamplona/Kassel, Universidad de Navarra/Reichenberger, 1994.

Díaz Balsera, Viviana, Calderón y las quimeras de la culpa. Alegoría, seducción y resistencia en cinco autos sacramentales, West Lafayette, Indiana, Purdue University Press, 1997.

Escosura, Patricio de la, «El demonio como figura dramática en el teatro de Calderón», Revista de España, 45, 1875, pp. 337-356 y 433-452.

Forestier, Georges, Le Théâtre dans le théâtre sur la scène française du XVIIe siècle, Genève, Droz, 2ª ed., 1996.

Hermenegildo, Alfredo, Javier Rubiera y Ricardo Serrano, «Más allá de la ficción teatral: el metateatro», Teatro de palabras, 5, 2011 (http://www.uqtr.ca/teatro/ teapal/TeaPalNum05.html).

Hornby, Richard, Drama, Metadrama, and Perception, Lewisburg, Bucknell, 1986.

Kowzan, Tadeusz, Théâtre miroir. Métathéâtre de l'Antiquité au XXIe siècle, Paris, L'Harmattan, 2006. 
Kurtz, Barbara E., The Play of Allegory in the Autos Sacramentales of Pedro Calderón de la Barca, Washington, D. C., The Catholic University of America Press, 1991.

Martin, Vincent, El concepto de «representación» en los autos sacramentales de Calderón, Pamplona/Kassel, Universidad de Navarra/Reichenberger, 2002.

McGarry, M. Francis de Sales, The Allegorical and Metaphorical Language in the Autos Sacramentales of Calderón, Washington, D.C., The Catholic University of America, 1937.

Miller, Arthur, Death of a Salesman, ed. Gerald Weales, New York, The Viking Press, 1967.

Moncunill Bernet, Ramón, Antropología y teología en los autos sacramentales de Calderón, Vigo, Academia del Hispanismo, 2011.

Moncunill Bernet, Ramón, «El demonio en los autos sacramentales de Calderón», Theatralia, 15, Figuras del mal y personajes perversos en el teatro europeo, 2013, pp. 63-75.

Parker, Alexander A., The Allegorical Drama of Calderón, Oxford, The Dolphin Book, 1943.

Parker, Alexander A., «La teología sobre el demonio en el drama calderoniano», Estudios Escénicos, 4, 1959, pp. 7-48. El original inglés, «The Theology of the Devil in the Drama of Calderón», The Aquinas Society of London, Aquinas Paper, 32, 1958, puede verse también en Critical Essays on the Theatre of Calderón, Bruce W. Wardropper (ed.), New York, New York University Press, 1965, pp. 3-23.

Parker, Alexander A., Los autos sacramentales de Calderón de la Barca, Barcelona, Ariel, 1983.

Reyes Anzaldo, Celedonio, «Metateatro y paradoja: dos marcas barrocas en El gran teatro del mundo», Revista Destiempos, México, 29, 2011, sin pp.

Rull, Enrique, Arte y sentido en el universo sacramental de Calderón, Pamplona/ Kassel, Universidad de Navarra/Reichenberger, 2004.

Schmeling, Manfred, Métathéâtre et intertexte, Paris, Lettres Modernes, 1982.

Shakespeare, William, King Henry V, ed. T. W. Craik, «The Arden Shakespeare», Third Series, London, Methuen, 1995.

Shakespeare, William, Obras completas, ed. Luis Astrana Marín, Madrid, Aguilar, 1964.

Suárez, Juan Luis, El escenario de la imaginación: Calderón en su teatro, Pamplona, Eunsa, Anejos de Rilce, 2002.

Thacker, Jonathan, Role-Play and the World as Stage in the Comedia, Liverpool, Liverpool University Press, 2002. 
Weir, Lucy Elizabeth, The Ideas Embodied in the Religious Drama of Calderón, Lincoln, University of Nebraska, 1940.

Woodward, Leslie J., «Suppositio in Calderón's No hay más fortuna que Dios», en Calderón and the baroque tradition, Kurt Levy, Jesús Ara y Gethin Hughes (eds.), Waterloo (Ontario, Canadá), Wilfrid Laurier University Press, 1985, pp. 41-46. 